\title{
Effect of Alloy Grain Size on the High-Temperature Oxidation Behavior of the Austenitic Steel TP 347
}

\author{
Vicente Braz, Trindade*, Ulrich Krupp, Behzad Zandi Hanjari, Songlan Yang, Hans-Jürgen Christ \\ Institut für Werkstofftechnik, Universität Siegen, Germany
}

Received: July 19, 2004; Revised: June 20, 2005

\begin{abstract}
Generally, oxide scales formed on high $\mathrm{Cr}$ steels are multi-layered and the kinetics are strongly influenced by the alloy grain boundaries. In the present study, the oxidation behaviour of an austenite steel TP347 with different grain sizes was studied to identify the role of grain-boundaries in the oxidation process. Heat treatment in an inert gas atmosphere at $1050{ }^{\circ} \mathrm{C}$ was applied to modify the grain size of the steel TP347. The mass gain during subsequent oxidation was measured using a microbalance with a resolution of $10^{-5} \mathrm{~g}$. The scale morphology was examined using SEM in combination with energy-dispersive X-ray spectroscopy (EDS). Oxidation of TP347 with a grain size of $4 \mu \mathrm{m}$ at $750{ }^{\circ} \mathrm{C}$ in air follows a parabolic rate law. For a larger grain size $(65 \mu \mathrm{m})$, complex kinetics is observed with a fast initial oxidation followed by several different parabolic oxidation stages. SEM examinations indicated that the scale formed on specimens with smaller grain size was predominantly $\mathrm{Cr}_{2} \mathrm{O}_{3}$, with some $\mathrm{FeCr}_{2} \mathrm{O}_{4}$ at localized sites. For specimens with larger grain size the main oxide is iron oxide. It can be concluded that protective $\mathrm{Cr}_{2} \mathrm{O}_{3}$ formation is promoted by a high density of fast grain-boundary diffusion paths which is the case for fine-grained materials.
\end{abstract}

Keywords: austenitic steel, $\mathrm{Cr}_{2} \mathrm{O}_{3}$ formation, grain boundary diffusion, high-temperature oxidation

\section{Introduction}

The formation of a protective $\mathrm{Cr}_{2} \mathrm{O}_{3}$ scale is required to avoid degradation by severe corrosion processes for alloys used in high temperature (up to $1000^{\circ} \mathrm{C}$ ). A number of investigations $\mathrm{s}^{1-5}$ have been carried out to improve the understanding of the growth mechanism of $\mathrm{Cr}_{2} \mathrm{O}_{3}$ scales. The influence of grain size of the oxide ${ }^{6-7}$ as well as the effect of doping by rate earth elements (e.g. yttrium or cerium) on the growth kinetics of $\mathrm{Cr}_{2} \mathrm{O}_{3}$ have been carefully investigated and even the diffusion coefficients of chromium and oxygen in the bulk and along grain boundaries of $\mathrm{Cr}_{2} \mathrm{O}_{3}$ are available. It is well established ${ }^{5,8,9}$ that $\mathrm{Cr}_{2} \mathrm{O}_{3}$ scales grow by counter-current diffusion of $\mathrm{Cr}$ and $\mathrm{O}$.

In addition to the understanding of the mechanisms of $\mathrm{Cr}_{2} \mathrm{O}_{3}$ scales growth, it is important to know the minimum bulk concentration of $\mathrm{Cr}$, which is necessary to form a protective scale on the entire surface, in order to prevent oxidation of the base material, e.g. Fe or $\mathrm{Ni}$. Several investigations ${ }^{10}$ reported a minimum value of $\mathrm{Cr}$ in the range between 18 wt. (\%) and 20 wt. (\%). However, this concentration range may depend strongly on the diffusion properties of $\mathrm{Cr}$ in the alloy. As a consequence, the grain size of the alloy should play an important role for the supply of $\mathrm{Cr}$ to the alloy/oxide interface, since the diffusivity of $\mathrm{Cr}$ along grain boundaries is much higher than that in the bulk ${ }^{11}$.

In the present study, the oxidation behaviour of the austenitic steel TP347, which is used in superheaters of power plants, with different grain sizes was studied to quantify the role of grain-boundaries on the oxide scale formation.

\section{Material and Experimental Procedure}

The chemical composition of the austenitic steel TP347 is given in Table 1 . The initial grain size of $4 \mu \mathrm{m}$ was coarsened to a grain size of $65 \mu \mathrm{m}$ by applying a heat treatment at $1050{ }^{\circ} \mathrm{C}$ in inert gas atmosphere for 112 hours.

Samples with a dimension of $(10 \times 10 \times 3) \mathrm{mm}^{3}$ were used for thermogravimetric study. The samples were ground using $\mathrm{SiC}$ paper down to 1200 grid. They were finally cleaned ultrasonically in ethanol prior to oxidation. Hole of $1 \mathrm{~mm}$ diameter serve for hanging the samples in a thermobalance by means of a quartz thread. Isothermal thermogravimetry was carried out using a microbalance with a resolution of $10^{-5} \mathrm{~g}$ in combination with an alumina reaction chamber and a $\mathrm{SiC}$ furnace. After oxidation the specimens were embedded in epoxy and carefully polished using diamond paste down to $1 \mu \mathrm{m}$ and cleaned ultrasonically in ethanol. The oxide layers were analysed using scanning electron microscopy (SEM) in combination with energy-dispersive X-ray spectroscopy (EDX).

\section{Results and Discussion}

Figure 1 shows the thermogravimetrically measured oxidation kinetics of TP347 of different grain sizes during exposure at $750{ }^{\circ} \mathrm{C}$ to laboratory air. The sample with a grain size of $4 \mu \mathrm{m}$ obeys a parabolic rate law. At a grain size of $65 \mu \mathrm{m}$, oxidation kinetics is more complex and exhibit a stepwise parabolic oxidation.

Figure 1 Thermogravimetrically measured oxidation kinetics of TP347 with different grain sizes exposed at $750{ }^{\circ} \mathrm{C}$ to laboratory air for 120 hours.

Table 1. Chemical composition (in wt. (\%)) of the austenitic steel TP 347.

\begin{tabular}{lcccccc}
\hline $\mathrm{C}$ & $\mathrm{Cr}$ & $\mathrm{Si}$ & $\mathrm{Ni}$ & $\mathrm{Mn}$ & $\mathrm{Nb}$ & $\mathrm{Fe}$ \\
\hline 0.04 & 17.5 & 0.29 & 10.7 & 1.84 & 0.56 & Bal. \\
\hline
\end{tabular}


Figure 2 shows cross sections of scales formed on TP347 with different alloy grain sizes after oxidation in laboratory air at $750{ }^{\circ} \mathrm{C}$ for 120 hours.

For the fine-grained specimen a very thin protective $\mathrm{Cr}_{2} \mathrm{O}_{3}$ scale is formed, but at some sites, this oxide layer is not totally protective and allows the subsequent formation of iron oxide nodules (Figure 2a), which grow outward and inward. On the coarse-grained specimen the oxide scale consists of an outer scale of iron oxide and an inner scale of mixed oxide phases containing $\mathrm{Fe}, \mathrm{Cr}, \mathrm{Mn}$ and $\mathrm{Ni}$, similar to the oxide nodules formed on the fine-grained specimens. EDS element mappings of this scale are shown in Figure 3

It can be seen in Figure 4a that the main oxide formed on top of the grain interior of the coarse-grained specimen is iron oxide while an $\mathrm{Cr}$-enriched oxide is formed along the grain boundaries. The formation of a protective $\mathrm{Cr}_{2} \mathrm{O}_{3}$ scale on specimens with the smaller grain size is favoured by a higher $\mathrm{Cr}$ flux from the substrate bulk to the substrate/oxide interface as a consequence of the higher grain boundary density (Figure 4b).

Using literature data for the $\mathrm{Cr}$ diffusion coefficient in the bulk and along grain boundaries of a $\mathrm{Fe}_{18} \mathrm{Cr}_{10} \mathrm{Ni}$ steel ${ }^{11}$ in combination with equations for the $\mathrm{Cr}$ flux from the bulk to the specimen surface derived by Lobb and Evans ${ }^{1}$, a considerable contribution of the grain boundary diffusion to $\mathrm{Cr}_{2} \mathrm{O}_{3}$ scale formation on specimens with small grain size must be assumed (Figure 5). Figure 5 also shows that the $\mathrm{Cr}$ flux along grain boundaries for the specimen with small grains is strongly influenced by the grain boundary width. Unfortunately, the grain boundary width can not be defined precisely. According to Fisher ${ }^{12}$ this value should be in the range of (0.5-1) nm.

The formation of $\mathrm{Cr}_{2} \mathrm{O}_{3}$ is particularly facilitated when the alloy grain size is smaller than $5 \mu \mathrm{m}$ (Figure 6 ). Figure 6 promotes the idea of using engineered materials, such as coatings consisting of $\mathrm{Cr}_{2} \mathrm{O}_{3}$ forming alloys, with very small grain sizes.

From the thermodynamic point of view, a rather low concentration of $\mathrm{Cr}$ is sufficient in order to form a $\mathrm{Cr}_{2} \mathrm{O}_{3}$ scale on $\mathrm{Fe}-\mathrm{Cr}$ steel. However, the critical minimum concentration is much higher than that predicted by the thermodynamic analysis, when the kinetics of $\mathrm{Cr}$ supply to the alloy/oxide interface is taken into account. As shown in this study, the alloy grain size is an important factor to be considered. As a consequence of the high $\mathrm{Cr}$ diffusivity along alloy grain boundaries, the fine-grained alloy requires a smaller $\mathrm{Cr}$ concentration than the coarse-grained alloy to form a slow growing $\mathrm{Cr}_{2} \mathrm{O}_{3}$ scale on the entire surface of the specimen.

It is also important to mention the effect of easy $\mathrm{Cr}_{2} \mathrm{O}_{3}$ oxide nucleation on the fine-grained specimen as reported by Lobb and Evans ${ }^{1}$, in addition to the higher flux of $\mathrm{Cr}$ along grain boundaries of the alloy with smaller grain. Both reasons may facilitate the formation of a protective $\mathrm{Cr}_{2} \mathrm{O}_{3}$ scale in a synergetic manner.

Once the oxide growing on the material is mainly $\mathrm{Cr}_{2} \mathrm{O}_{3}$, it is possible to predict the growth kinetics of the oxide scale by using the model developed by Carl Wagner ${ }^{13}$ and successfully applied by Tsai et al. ${ }^{5}$ to $\mathrm{Cr}_{2} \mathrm{O}_{3}$. Diffusion of metal cations and oxygen anions within the bulk oxide and oxide grain boundaries were taken into account separately. The diffusion coefficient applied are those measured by Sabioni et al. ${ }^{14}$. Figure 7 shows the $\mathrm{Cr}_{2} \mathrm{O}_{3}$ thickness as a function of time calculated on the basis of sole diffusion i) through the oxide bulk, ii) along oxide grain boundaries; and iii) using an effective diffusion coefficient of $\mathrm{Cr}$ and $\mathrm{O}$, according to Sabioni et al. ${ }^{14}$.

The oxide scale growth calculated on the basis of the effective value of the diffusion coefficient of $\mathrm{Cr}$ and $\mathrm{O}$ within the $\mathrm{Cr}_{2} \mathrm{O}_{3}$ scale is in reasonable agreement with the experimental data obtained in this study. The small deviation found can mainly be attributed to the formation of iron oxide nodules at some locations, which leads to higher oxidation kinetics. The values calculated by using only bulk

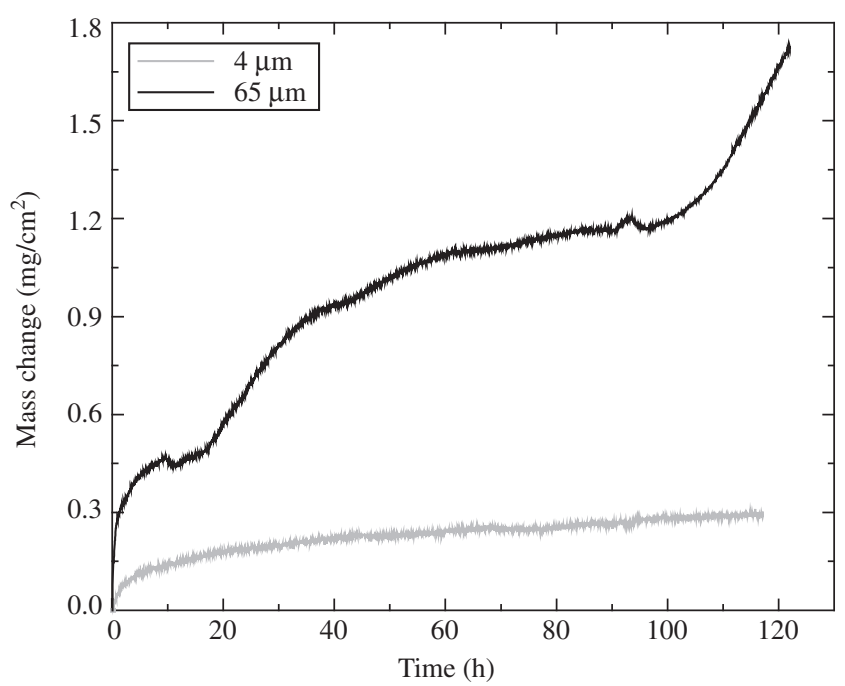

Figure 1. Thermogravimetrically measured oxidation kinetics of TP347 with different grain sizes exposed at $750{ }^{\circ} \mathrm{C}$ to laboratory air for 120 hours.

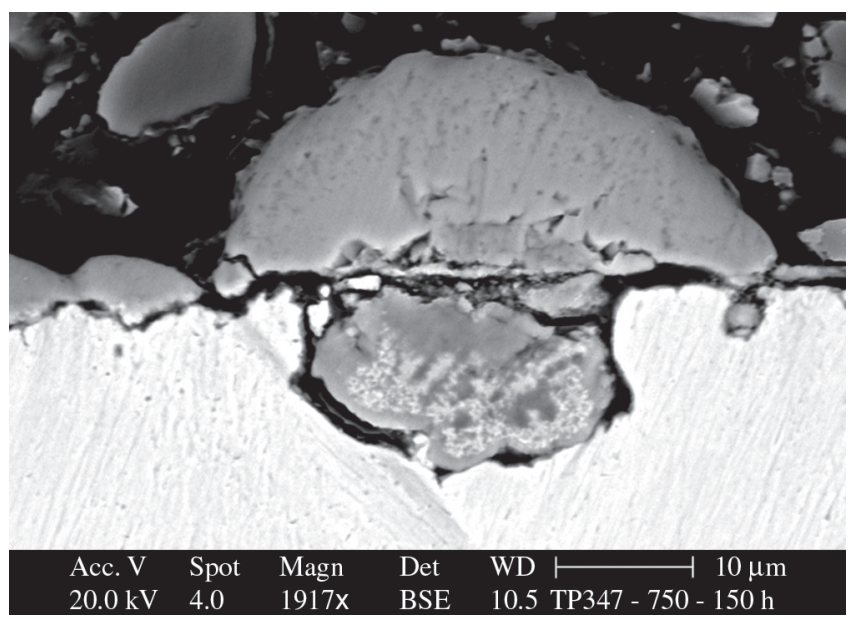

(a)

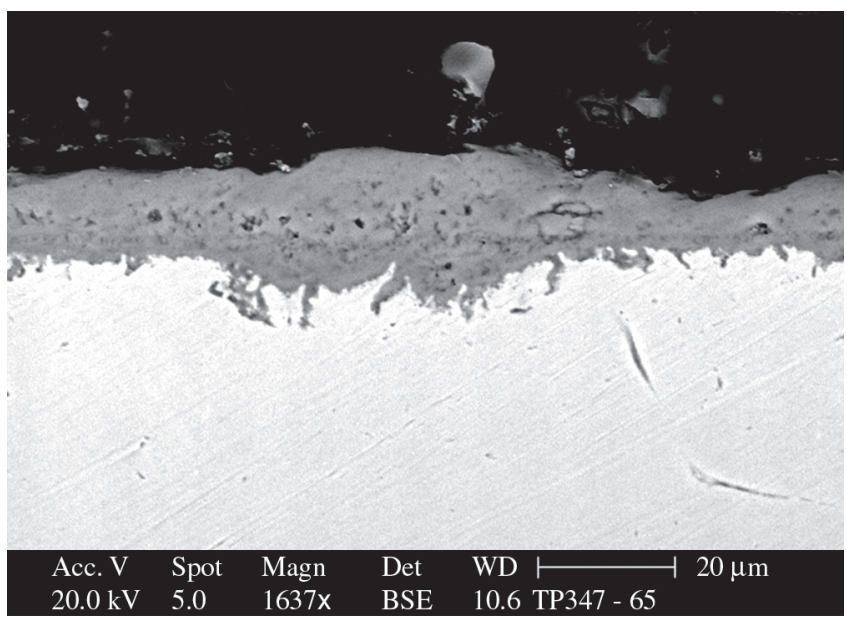

(b)

Figure 2. Cross sections of the oxide scales formed on TP347 after oxidation in laboratory air at $750{ }^{\circ} \mathrm{C}$ for 120 hours: a) fine-grained; and b) coarsegrained condition. 

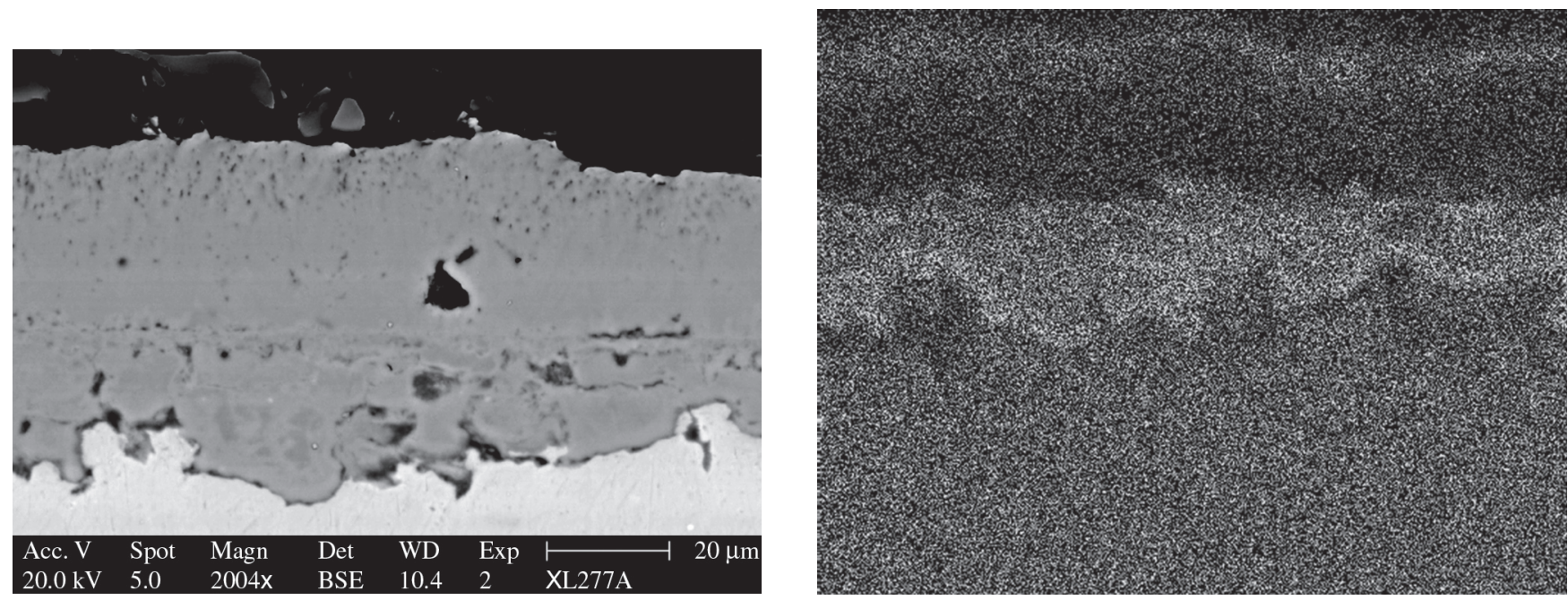

$\mathrm{Mn}$
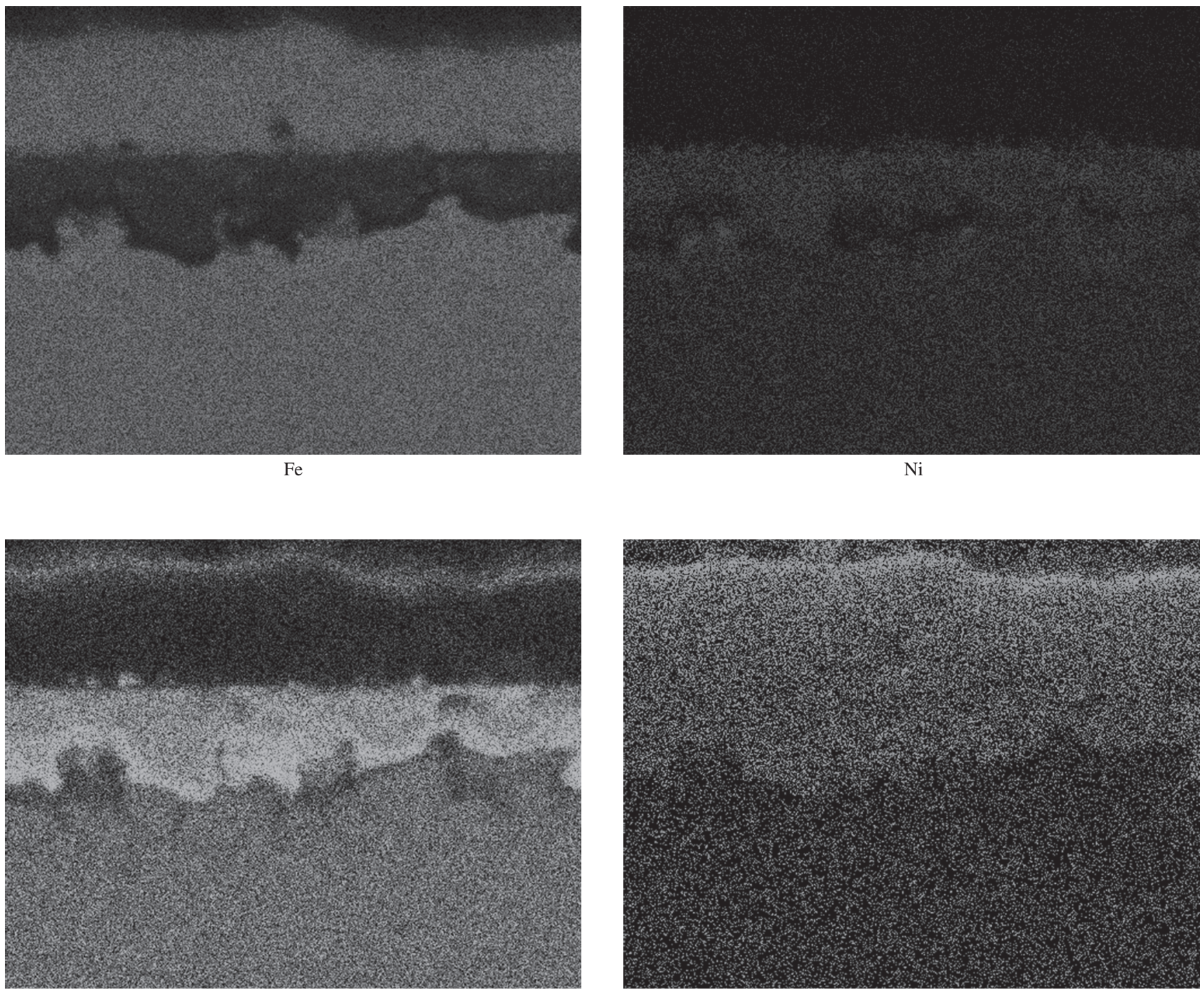

Figure 3. Cross section and corresponding EDS mappings of the oxide scale formed on TP347 with grain size of $65 \mu \mathrm{m}$ after oxidation in laboratory air at $750{ }^{\circ} \mathrm{C}$ for 120 hours. 
diffusion and only grain boundary diffusion are tremendously lower or higher, respectively, than the value observed experimentally.

\section{Conclusions}

A slowly growing $\mathrm{Cr}_{2} \mathrm{O}_{3}$ oxide was observed on specimens with small grain size due to the high density of grain boundaries leading

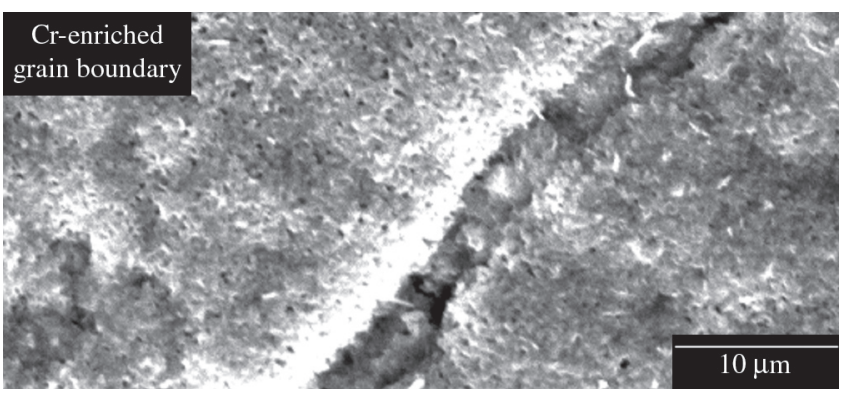

(a)

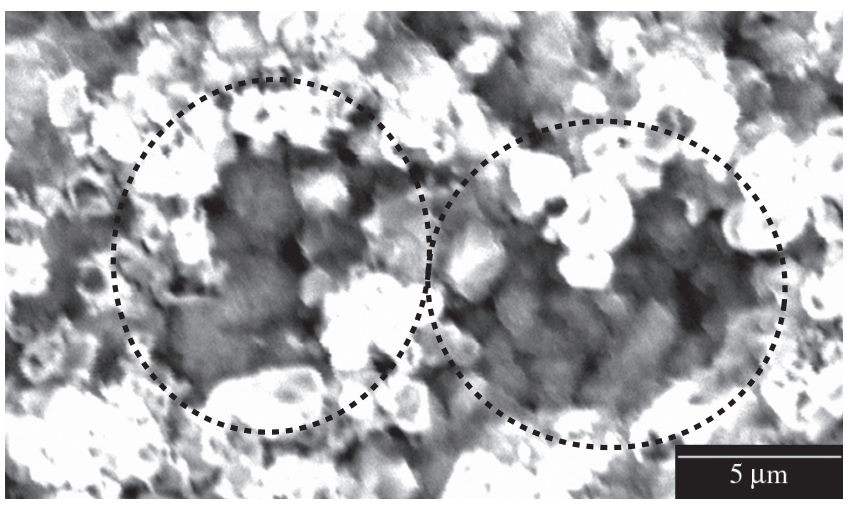

(b)

Figure 4. Surface of the scale formed on TP 347 at $750{ }^{\circ} \mathrm{C}$ after 1.5 hours exposured to air: a) iron oxide formed on top of the grain interior and $\mathrm{Cr}$-enriched oxide formation along substrate grain boundaries of the coarse-grained specimen $(\mathrm{d}=65 \mu \mathrm{m})$; and $\mathrm{b})$ formation of a thick $\mathrm{Cr}_{2} \mathrm{O}_{3}$ layer along grain boundaries on the fine-grained specimen (dashed lines).

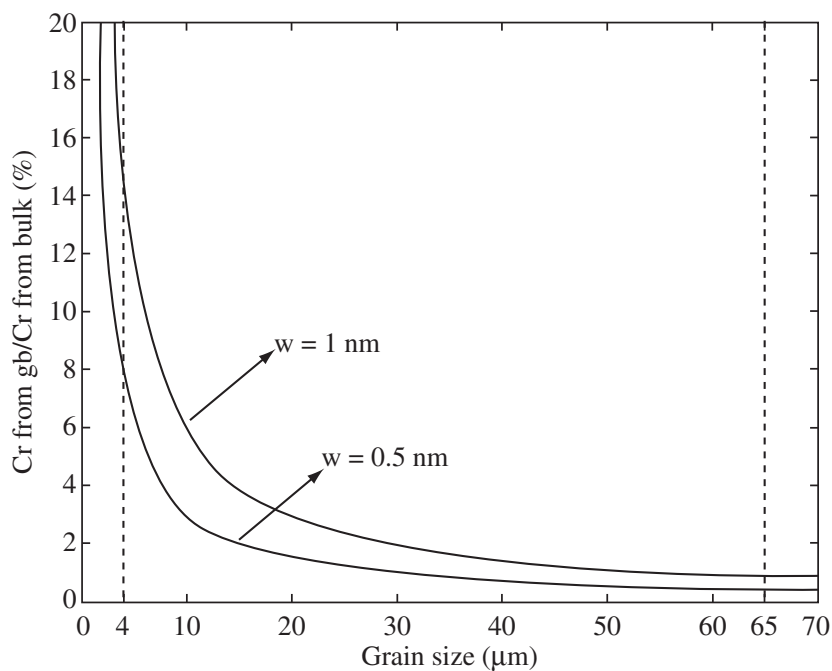

Figure 5. Effect of the grain size and grain boundary width on the flux of $\mathrm{Cr}$ in TP 347 at $750{ }^{\circ} \mathrm{C}$.

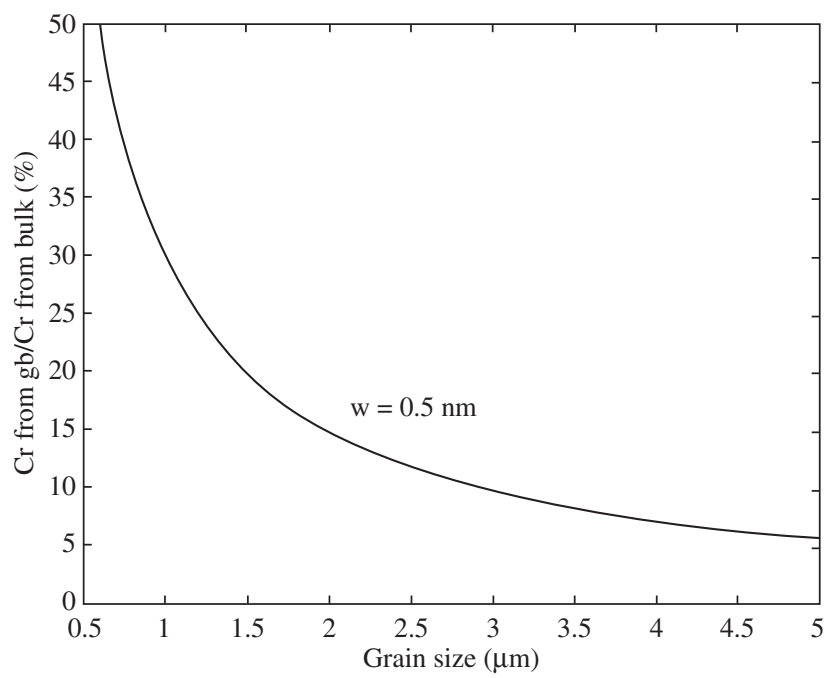

Figure 6. Cr flux along grain boundaries of TP 347 at $750{ }^{\circ} \mathrm{C}$ with very small grain size.
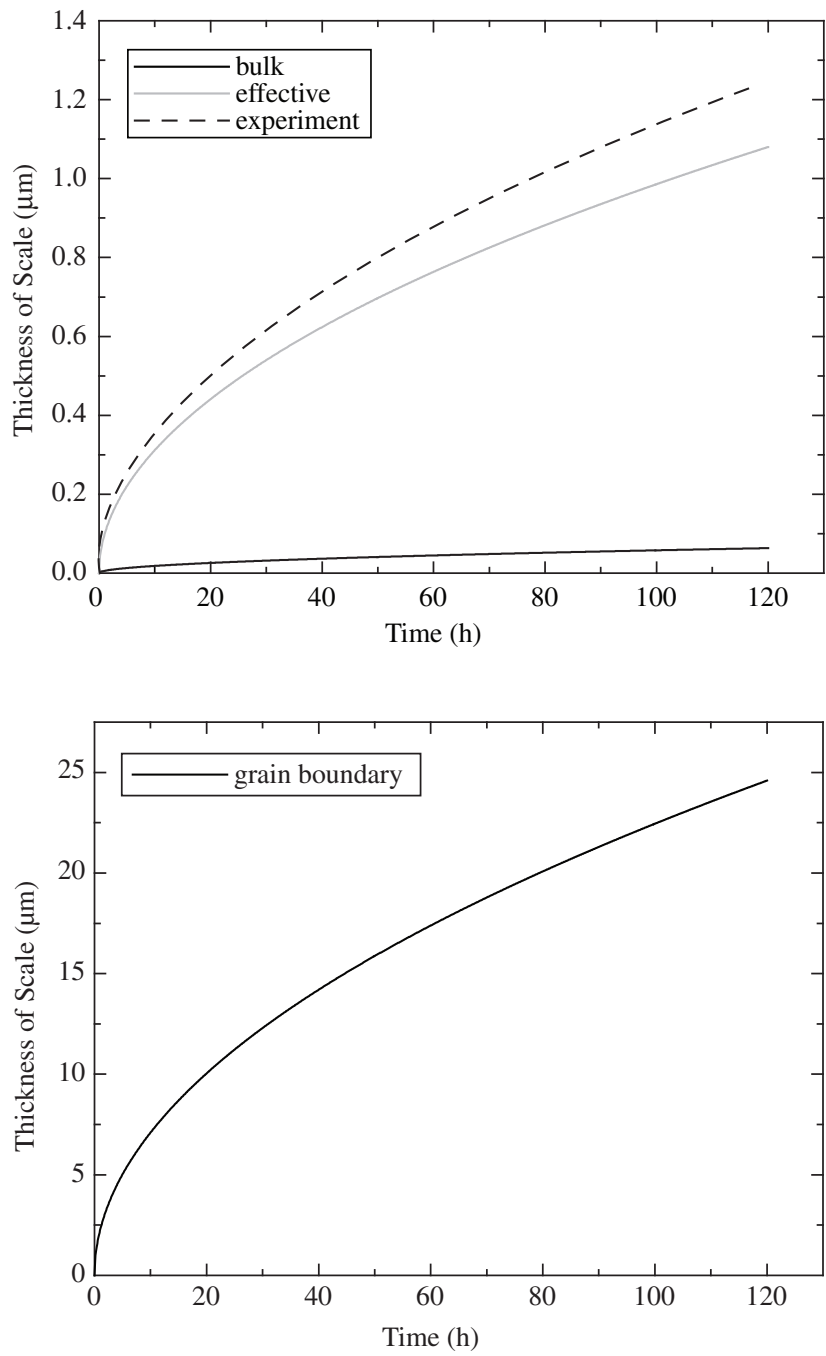

Figure 7. Calculated and measured kinetics of $\mathrm{Cr}_{2} \mathrm{O}_{3}$ scale growth on the fine-grained specimen at $750{ }^{\circ} \mathrm{C}$ during exposure to air. 
to fast outward $\mathrm{Cr}$ transport along the substrate grain boundaries. Specimens with larger grain size form iron oxide growing outward and a mixed $\mathrm{Fe}, \mathrm{Cr}, \mathrm{Mn}$ and $\mathrm{Ni}$ oxide growing inward. When adding $\mathrm{Cr}$ to high-temperature alloys in order to ensure the formation of a slowly growing superficial $\mathrm{Cr}_{2} \mathrm{O}_{3}$, one has to consider the high diffusivity of $\mathrm{Cr}$ along substrate grain boundaries, which may significantly contribute to the $\mathrm{Cr}$ transport toward the substrate/oxide interface in materials with small grain size. Therefore, a alloy with larger grain size requires a higher bulk $\mathrm{Cr}$ concentration to establish a protective $\mathrm{Cr}_{2} \mathrm{O}_{3}$ scale. Precise information about the grain boundary width would be necessary in order quantitatively assess the $\mathrm{Cr}$ flux resulting from the substrate grain boundaries. Nevertheless, in the case of the fine-grained specimens a prediction of the growth kinetics is possible by applying Wagner`s theory for the case of a single external oxide scale formation using the effective diffusion coefficient of $\mathrm{Cr}$ and $\mathrm{O}$ within the oxide scale.

\section{Acknowledgments}

This research has been supported by the EU project OPTICORR and by the Brazilian Research Foundation (CAPES) through a fellowship to one of the authors (V.B.Trindade).

\section{References}

1. Lobb RC, Evans HE. Formation of protective oxide film on chromiumdepleted stainless steel. Metal Science. 1981; 267-274.

2. Baer DR, Merz MD. Differences in oxides on large- and small-grained 304 stainless steel. Metallurgical Transactions A. 1980; 11A:1973-1980.
3. Dunning JS, Alman DE. Rawers, JC. Influence of silicon and aluminium additions on the oxidation resistance of a lean-chromium stainless steel. Oxidation of Metals. 2002; 57:409-425.

4. Pérez FJ, Pedraza F, Sanz C, Hiero MP, Gómez C. Effect of thermal cycling on the high temperature oxidation resistance of austenitic AISI 309S stainless steel. Materials and Corrosion. 2002; 53:231-238.

5. S. Tsai C, Huntz AM, Dolin C. Growth mechanism of $\mathrm{Cr}_{2} \mathrm{O}_{3}$ scales: Oxygen and chromium diffusion, oxidation kinetics and effect of ytrium. Materials Science and Engineering A. 1996; 212:6-13.

6. Basu SN, Yurek GJ. Yurek. Effect of alloy grain size and silicon content on the oxidation of austenitic Fe-Cr-Ni-Mn-Si alloys in pure $\mathrm{O}_{2}$. Oxidation of Metals. 1991; 36:281-315.

7. Yurek GJ, Eisen D, Garrat-Reed A. Oxidation Behavior of a Fine-Grained Rapidly Solidified 18-8 Stainless Steel. Metallurgical Transactions A. 1982; 13A:473-485.

8. Huntz, AM. Parabolic Laws During High Temperature Oxidation: Relations with the Grain Size and Thickness of the Oxide. Journal of Materials Science Letters. 1999; 18:1981-1984.

9. Smith, AF. The Diffusion of Chromium in Type 316 Stainless Steel. Metal Science. 1975; 9:375-378.

10. Bürgel R. Handbuch Hochtemperaturwerkstofftechnik. Friedr. Vieweg \& Sohn Verlagsgesellschaft mbH, Braunschweig, 1998.

11. Kaur I, Gust W. Fundamentals of Grain and Interphase Boundary Diffusion. Ziegler Press, Stuttgart; 1988.

12. Fisher JC. Calculation of diffusion penetration curves for surface and grain boundary diffusion. Journal of Applied Physics. 1951; 22:74-82.

13. Wagner C. Atom Movements. American society of metals, Cleveland 1951.

14. Sabioni ACS, Lesage B, Huntz AM, Pivin J, Monty C. Self-diffusion in $\mathrm{Cr}_{2} \mathrm{O}_{3}$, I. Chromium diffusion in single crystals. Philosophical Magazine A. 1992; 66:333-350. 